\title{
Risk Factors for Teenage Pregnancy and Youth Health Needs in Nkalashane, Swaziland
}

\author{
Article by Busisiwe Prudence Tsabedze \\ M.Sc Clinical Psychology, Texila American University, Swaziland \\ E-mail: busiedonsie@yahoo.com
}

\begin{abstract}
Teenage pregnancy is an enormous challenge in Swaziland. The Nkalashane clinic (Lubombo region) observed a growing number of teenage pregnancies. In 2014 alone, 49\% of pregnancies were among women who had their first child before their 19th birthday. The objective of this study was to investigate risk factors of teenage pregnancy among teenage mothers (TM), teenage fathers (TF), and services needed by the at-risk youth (ARY) to prevent teenage pregnancy. Participants were identified from the clinic's registers, snowball sampling, and the 3 schools in the area. Participants completed questionnaires and focus group discussions (FGDs). Data was summarized using descriptive statistics. 43 TM, 8 TF and 73 ARY participated. TM had a family history of teenage pregnancy (42\%), had guardians with only a primary education (63\%), and had older partners (mean age difference 5.2 years). Only $44 \%$ of TM and 38\% of TF reported using contraception at the time of first pregnancy. Reasons for not using contraception included: lack of knowledge on pregnancy (47\%) and contraception (38\%). TM reported engaging in transactional sex due to peer pressure or lack of money. In FGDs, lack of knowledge, peer pressure, difficult access to contraception, and lack of parental guidance were discussed as risk factors. The main risk factors were: lack of knowledge; peer pressure; intergenerational sex; and difficult access to contraceptives. Recommendations include: offering comprehensive sexual education to both youth and adults; strengthening the relationship between schools, communities, and clinics; training clinic staff on youth-friendly services.
\end{abstract}

\section{Introduction}

Teenage pregnancy is a global public health concern. According to the World Health Organization (WHO), 16 million women aged 15-19 give birth each year (WHO, 2014). Ninety-five per cent of these births occur in low- and middle-income countries (WHO, 2014). Although teenage pregnancies account for $11 \%$ of all births worldwide, they account for $23 \%$ of the overall burden of disease due to pregnancy and childbirth (WHO, 2014). Therefore, teenage pregnancy remains a major contributing factor to maternal and child mortality. Teenage pregnancy is also associated with many negative outcomes, including anaemia, HIV and other sexually transmitted infections, postpartum haemorrhage and mental disorders, such as depression. Teenage pregnancy is also linked to other social factors at different levels including individual, environmental, peer and culture factors that have been shown in previous studies to influence adolescent behaviour (Goucelea W. O., 2009).

Swaziland, like many lower-middle income countries, is faced with the enormous challenge of teenage pregnancy. Overall, more than one in five women reported to have had their first live birth before their eighteenth birthday (MICS, Government of Swaziland, 2010).

Many factors contribute to this phenomenon of teenage pregnancy in Swaziland. For example, the Multiple Indicator Cluster Survey (MICS; Government of Swaziland, 2010) found that $35 \%$ of women with only primary education had a live birth by the age of 18 compared with $4 \%$ of women with tertiary education. Early childbearing was also found to be associated with level of wealth in Swaziland, with teenage pregnancy being more common among women in the poorest quintile (MICS, Government of Swaziland, 2010). The young age structure of the country (approximately $60 \%$ of the population is under the age of 30 
years (DHS, Central Statistical Office, 2007)), and the HIV/AIDS epidemic has likely worsened the situation.

Data from the facility shows the following an alarming number of women young who are multi para, having had their first pregnancy when they were teenagers (26\% in 2014 Table A ; and the number of women who attended antenatal care that were less than 19 years (18\% in 2013 in 2014, resulting in 49\% of pregnancies in 2014 that were teenage pregnancies.

\begin{tabular}{|l|l|l|l|l|}
\hline $\begin{array}{l}\text { Table A: Teenage } \\
\text { pregnancies at } \\
\text { Nkalashane Clinic } \\
\text { between 20111 and 2014 }\end{array}$ & 2011 N (\%) & 2012 N(\%) & 2013 N (\%) & 2014 N (\%) \\
\hline $\begin{array}{l}\text { Totalpregnant women all } \\
\text { ages }\end{array}$ & 83 & 90 & 88 & 91 \\
\hline Pregnant women 19 years & $13(16 \%)$ & $12(13 \%)$ & $16(18 \%)$ & $21(23 \%)$ \\
\hline $\begin{array}{l}\text { Pregnant women 23 years } \\
\text { of age with 2 or more } \\
\text { pregnancies }\end{array}$ & $17(20 \%)$ & $27(20 \%)$ & $21(24 \%$ & $24(26 \%)$ \\
\hline $\begin{array}{l}\text { Total number of teenage } \\
\text { pregnancies }\end{array}$ & $30(36 \%)$ & $39(43 \%)$ & $37(42 \%$ & $45(49 \%)$ \\
\hline
\end{tabular}

The aim of the study was to explore and describe teenagers and teenage mothers' and fathers' perceptions on factors and risks contributing to teenage pregnancy among the youth in Nkalashane, Swaziland. The objectives were to determine the risk factors contributing to teenage pregnancy among the youth in Nkalashane and to gather information on how best to increase positive links between and among youth, teenage pregnancy prevention programs, and community-based clinical services.

\section{Methods}

This study was divided in three parts, a descriptive retrospective study to understand the risk factors of teenage pregnancy, a descriptive cross-sectional study to understand the services that are needed by the at-risk youth in Nkalashane to prevent teenage pregnancy and descriptive cross-sectional study to understand the challenges faced by the facility staff to prevent teenage pregnancy.

Part 1: A descriptive retrospective study to understand the risk factors of teenage pregnancy

\section{Inclusion criteria}

Teenage mothers: a woman who fell pregnant for the first time before the age of 19;

Teenage fathers: a man who impregnated a partner before the age of 19 .

Sampling method: Teenage mothers were identified using clinic registers from 2013-2015 (ANC and PNC/Family Planning). Once identified, the client was called by the head nurse of Nkalashane Clinic. In addition, snowball sampling was used to reach other teenage mothers that might not have visited the facility during ANC. Teenage fathers were also sampled using snowball sampling method.

Data collection: The data collection took place in May 2015, over the course of 4 days. Teenage mothers were asked to come to the Nkalashane Clinic to participate in the study, while the teenage fathers were either interviewed at the Nkalashane Clinic or a place of convenience. Four trained peer educators obtained consent from participants, and facilitated the structured questionnaires. The questionnaires took approximately 50 minutes to complete. Participants were then asked to participate in a focus group discussion (FGD). Each FGD was conducted by two trained peer educators, and had an average of 10 participants. The duration of each FGD was approximately 45 minutes, and all FGDs were recorded using a tape recorder. FDGs were conducted in siSwati, the language of general communication in Swaziland. 
Part 2: A descriptive cross-sectional study to understand the services that are needed by the at-risk youth in Nkalashane to prevent teenage pregnancy.

Inclusion criteria: At-risk youth: someone between the ages of 12-19 years that has not yet fallen pregnant/impregnated someone. Participants had to be enrolled in one of the three targeted schools.

Sampling method: Participants were selected from three schools of the area: Nkalashane Primary School, Nkalashane High School, and Mbokojweni Secondary School. These schools were selected as a result of their proximity to the Nkalashane Clinic, and represented each school level. 26 participants (15 females and 11 males) were randomly selected from each school by the study team using class lists. Selected participants received an invitation letter and a consent form to retrieve their consent as well as their parent's consent.

Data collection: At each school, participants were divided into two groups: at-risk girls, and at-risk boys. Peer educators facilitated the questionnaires and FGDs, following the same methodology as Part 1 of the study.

Part 3: Descriptive cross-sectional study to understand the challenges faced by the facility staff to prevent teenage pregnancy.

Inclusion criteria: Nurses, orderlies, community workers and expert clients that were employed at Nkalashane Clinic at the time of the study.

Sampling method: Each staff member was asked by the study team whether they would like to be enrolled in the study.

Data collection: After retrieving their consent, each staff member answered the questionnaire. Due to small sample size, no FGD was conducted among the facility staff.

\section{Sample size}

The sample size of each group was determined using published information, taken from the Swaziland Demographic and Health Survey (Central Statistical Office, 2007), regarding the proportion of youth's knowledge regarding sexuality and safe sex. More specifically, the information used was: (1) Teenage mothers: the proportion of women aged 15-19 who were not exposed to any information source for family planning. (2) Teenage fathers: the proportion of men aged 15-19 who believe that contraception is a women's business. (3) Atrisk youth: the proportion of youth who ever had sex before 19 years old, by sex. Based on the sample size calculation and the throughput of the clinic, the study aimed at enrolling 40 teenage mothers, 25 teenage fathers, and 26 at-risk youth from each school (15 females and 11 males).

\section{Study definitions and instruments}

The questionnaires for teenage mothers/fathers and at-risk youth contained approximately 50 questions on respondent demographics (age, parents education level, family history of teenage pregnancy, etc.), emotional status (emotional support, depression, etc.), sexual behaviour and contraception (age of sexual debut, method of contraception used, etc.), safe sex knowledge (origin of information, knowledge score, methods of contraception known, etc.), healthy relations (dating older partner, peer pressure, etc.) and knowledge of services available at health facilities. At-risk youth were also asked their opinion about teenage pregnancy and its causes. The facility staff questionnaire had 15 questions which encompassed: socio-demographic characteristics, services provision (HIV testing and counselling, family planning services provision to teenagers), opinions on abortion and emergency contraception, and opinions about teenage pregnancy and youth-friendly services.

Family history of teenage pregnancy was defined as having your mother falling pregnant for the first time before the age of 19 years. Peer pressure was defined as feeling pressure from friends to do things that you do not want to. The depression score was calculated using the depression subscale of the EST-Q screening questionnaire (Aluoja et al. 1999). The Depression subscale consists of eight items encompassing cognitive and affective symptoms of depression, and each item is rated on a five-point scale ranging from 0 to 4 ( $0=$ not at all; 4 
$=$ all the time). The cut-off point for depression was a score $>11$, as previously defined by the literature (Ööpika et al. 2006, Liik, et al. 2013).

The knowledge on contraception score was calculated using 11 knowledge questions. The participants had to answer whether they think the statements were true or false and each answer was rated either 1 (correct answer) or 0 (wrong answer).

\section{Data analysis}

Questionnaires: Data entry was conducted using Microsoft Access 2007 (Microsoft Corporation, Redmond WA). The questionnaires were analysed using STATA version 12 (StataCorp, College Station TX). Categorical variables were summarized using frequency distributions, and continuous variables were summarized using descriptive statistics.

Focus groups discussions: FDGs were transcribed verbatim, and translated from siSwati into English. After three study team members read through the 11 transcripts several times, a coding schema was decided on by the study team. The coding schema followed the main themes of the study protocol: the risks factors of teenage pregnancy, the perception and knowledge of contraception and safe sex, and the recommendations for better youth-friendly services and to prevent teenage pregnancy. The FGDs were then thematically analysed using a rapid analysis method. ATLAS ti 7.5 (Scientific Software Development GmbH, Berlin) was used to support and verify themes and relationships between themes.

\section{Ethical considerations}

The study received ethical approval from the Swaziland Ministry of Health (MOH) Scientific and Ethics Committee. For each person who was contacted, the purpose of the research was explained and their voluntary participation was sought. All participants were assured that their name will not be recorded, and told that there will be no benefits or penalties for refusing or agreeing to participate in the study. Participants less than 18 years old that are pregnant or already a parent were considered as emancipated minor or mature adult, thus no written consent was required from the parents/guardians. The community and the schools involved were sensitised to the study prior to the data collection. The researchers contacted the Lomahasha Inkhundla as well as the Director of Education and Training and the Regional Education Officer from the Ministry of Education and Training (MOET) to retrieve their approval.

In terms of cultural sensitivity, the questionnaires and consent form were translated from English to siSwati by the study team, and were reviewed by the senior nurse of Nkalashane Clinic and the peer educators in order to ensure culturally sensitive wording while holding true to the questionnaire intent. The peer educators were trained to verbally administer the questionnaire in English and siSwati, two languages in which they are all fluent

\section{Results}

\section{Part 1: Descriptive retrospective study to understand the risk factors of teenage pregnancy}

\section{Quantitative findings: questionnaires among teenage mothers}

A total of 47 teenage mothers and 9 teenage fathers were enrolled in the study. However, 4 teenage mothers and 1 teenage father were excluded because they did not meet the inclusion criteria (they either had their first child after the age of 19, or did not report the age at which they had their first child). Table 1.1 presents the socio-demographic characteristics of the participants. Of the 43 teenage mothers, $42 \%$ had a family history of teenage pregnancy (i.e. their mother was $<19$ when having her first child), and the majority of teenage mothers' guardians either had no schooling, or only attended primary school. 


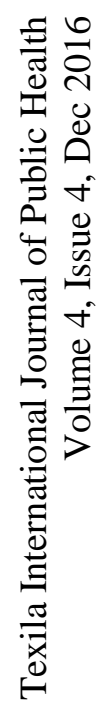

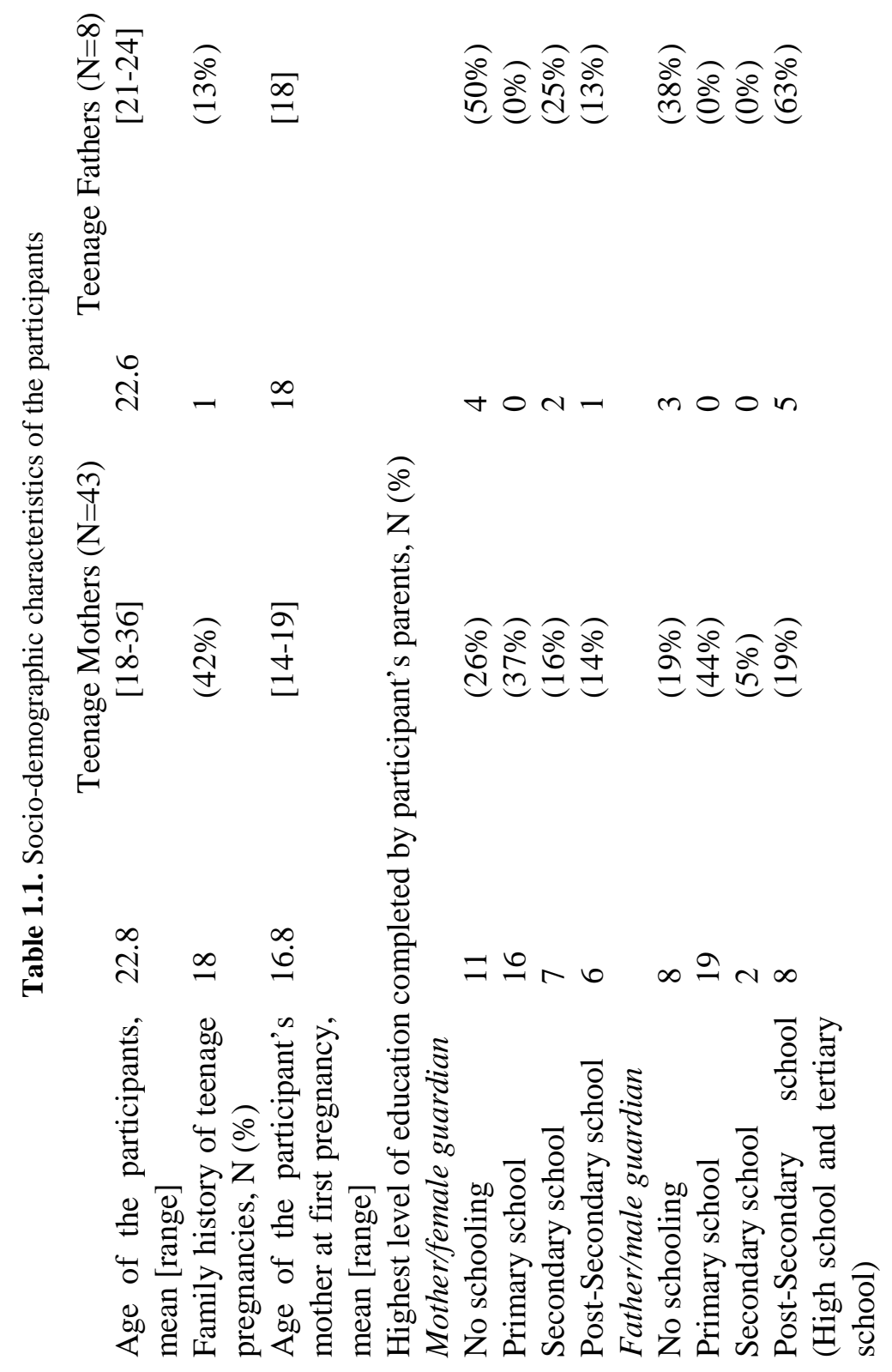


Texila International Journal of Public Health

Volume 4, Issue 4, Dec 2016

On average, the teenage mothers had their first child at the age of 17.6 years, while the teenage fathers had their first child at 18.5 years. The majority of participants were in school at the time of the first pregnancy ( $63 \%$ of the teenage mothers and $88 \%$ of the teenage fathers); however, while $57 \%$ of the teenage fathers went back to school after the first pregnancy, most of the teenage mothers (81\%) dropped out of school. All the teenage mothers were dating older partners (the average age difference between the participant and the partner being 5.2 years [range=1-14]) with high levels of education ( $44 \%$ with post-secondary). 
吾
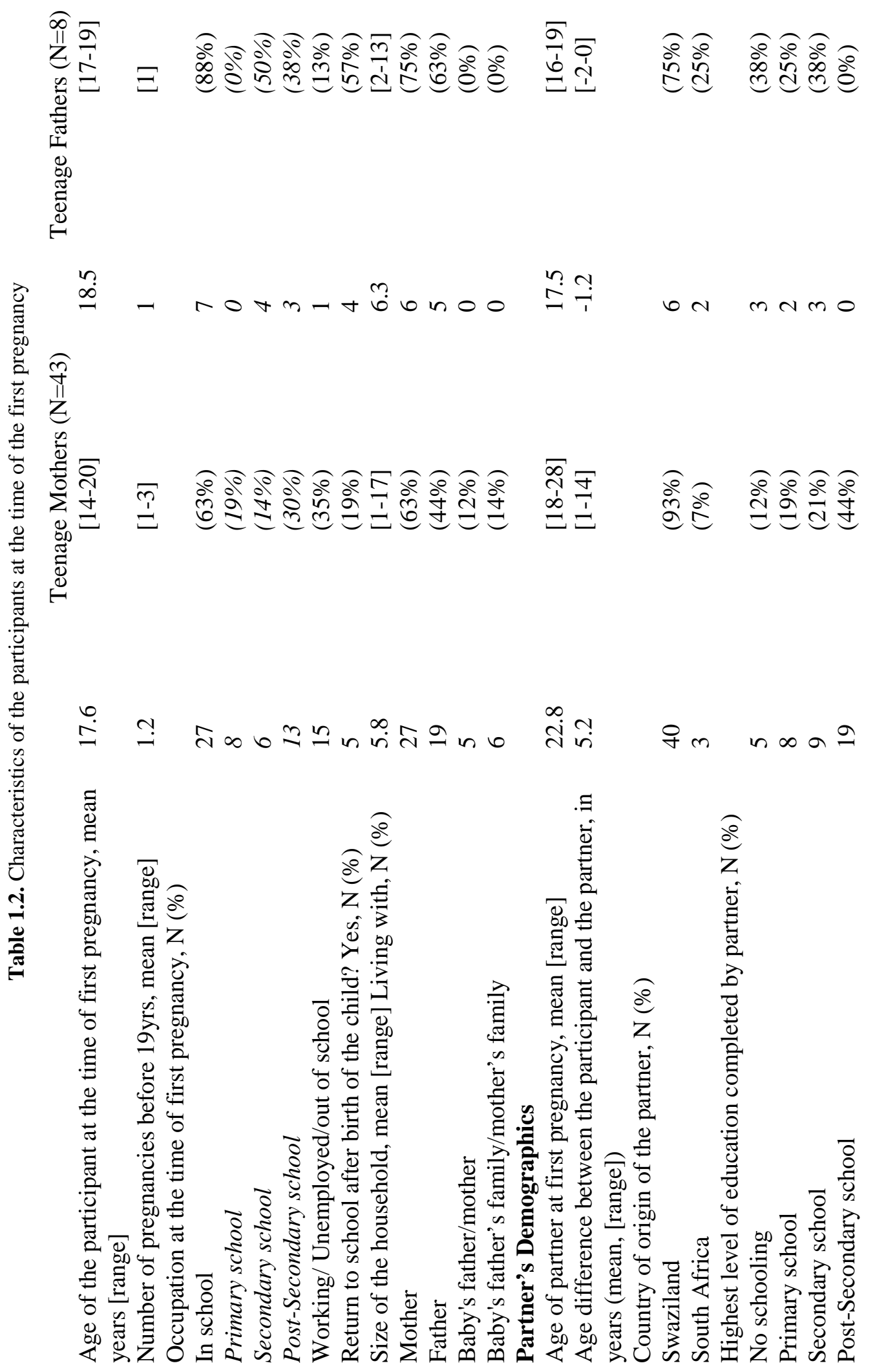
Texila International Journal of Public Health

Volume 4, Issue 4, Dec 2016

\section{Sexual behaviour and contraception use}

The average age of sexual debut was 16 years, for both teenage mothers and teenage fathers. However, $63 \%$ of the teenage fathers started having sex because they felt ready compared to only $30 \%$ of the teenage mothers. In terms of contraception use at the time of first pregnancy, only $44 \%$ of the mothers and $38 \%$ of the fathers reported using contraception, mainly condoms. According to the teenage mothers, the main reason why they got pregnant despite using contraception was because the condom broke. The table also shows the most frequently reported reasons for not using contraception; with the two most frequently reported reasons "I didn't think I could get pregnant" (58\%), "I did not know about contraception" (38\%). The teenage mothers further reported that they did not want to get pregnant (47\%) or did not know about pregnancy (35\%). On the other hand, 30\% reported that their partner wanted them to get pregnant.

Participant's knowledge about safe sex at the time of first pregnancy

$42 \%$ of the teenage mothers and $38 \%$ of the teenage fathers reported that they were not at all knowledgeable about sexuality, contraception and safe sex. The main sources of information about sexuality and contraception were health care workers (HCWs) and teachers. The participants were asked to cite all the contraception methods they knew about, and $51 \%$ of the teenage mothers and $50 \%$ of the teenage fathers were able to cite at least one correct method of contraception. On the other hand, $14 \%$ of the teenage mothers and $25 \%$ of the teenage fathers cited at least one ineffective method of contraception, mainly withdrawal. On average, the teenage mothers and fathers had high knowledge on contraception scores; however, there are still misunderstandings around safe sex. For instance, 23\% of the teenage mothers and $25 \%$ of the teenage fathers thought that "to be extra safe, it is good to use two condoms at once".

Support system, healthy behaviour and relation at the time of first pregnancy

Most teenage mothers reported strong family and friend networks at the time of first pregnancy (59\%) and did not experience peer pressure (52\%). However, teenage mothers had a high emotional state score (15.2), and 77\% were screened depressive by the EST-Q1 (i.e. emotional state score $>11$ ). None of the participants reported smoking or taking drugs at the time of the first pregnancy, however $77 \%$ of the teenage fathers and $13 \%$ of the teenage mothers reported drinking. Among teenage mothers, 64\% reported that they were dating someone 5 years older at the time of the first pregnancy, and they were also relying on the baby's father $(56 \%)$ or his family (16\%) for financial support, while most of the teenage fathers had no external source of financial support (63\%). Even though $60 \%$ of the teenage mothers reported that both they and their partner were responsible in preventing pregnancy, $71 \%$ reported that their partners had more control than them in important decisions that affected their relationship.

\section{Qualitative findings: focus group discussions among teenage mothers}

Five FGDs among teenage mothers were conducted, however due to small sample size no teenage fathers participated in a FGD.

Risks factors of teenage pregnancy

\section{Lack of knowledge on contraception and relationships}

The participants highlighted that one of the main factors related to teenage pregnancy was the lack of knowledge. Teenage mothers were lacking information on safe sex and contraception at the time of first pregnancy. For instance, even if teenage mothers were familiar with condoms, only a few had heard of injections, birth control pills, IUD, or implants. Many adolescent girls and young women entered into relationships without understanding their own rights as individuals, what may be expected of them by their partners, and how to communicate and negotiate for their own safety and protection.

"We are hiding the truth from the children. We didn't tell them that they will fall pregnant if they have sex". 
"You find that the child grows up and get a boyfriend without having proper information and then they fall pregnant."

"Some people tend to think they know more when in actual fact they don't know anything."

"In most cases the young girls don't know the meaning of being in a relationship and the only thing that will happen is that they will have sex as a definition for being in that relationship. The next thing obviously is pregnancy”.

\section{Peer pressure}

The FGDs strongly highlighted that peer pressure was a risk factor of teenage pregnancy. Peers often persuaded the participants to engage in sex with older people so that they could get money, phones or other material things in exchange. Furthermore some respondents reported engaging in relationships in order to fit-in a group and not to feel as if they were missing out.

"Young people will tell each other that they have money because they are in a relationship with a certain older man and would suggest to the friend to do the same if they wanted money as well.”

\section{Lack of parental interaction}

Lack of parental guidance and support was reported as contributing to teenage pregnancy. In addition some teenage mothers reported that they were left with their grandparents who failed to advise them properly about sexuality. Being needy (financially or emotionally) or having lost your parents also seemed to have played a role in how vulnerable the teenagers were to peer pressure. It also was communicated that some parents did not execute disciplinary measures when their teenagers came home at night or with gifts.

\section{Intergenerational and transactional sex}

It emerged that teenage mothers found themselves pregnant because they often engaged in relationships with older men. Intergenerational or transactional sex was often caused by peer pressure and wanting to get money and other material things. The study pointed out that usually older men do not want to use condoms, and the teenage girls found themselves with no negotiation power. The teenage mothers further indicated that older partners had more control in the relationship and sometimes forced them to do things against their will. Teenage mothers often asserted that accepting financial or material assistance from a man meant accepting sex on his terms, which very often means sex without condoms.

"Now if it happens that you agree on something, sugar-daddies don't want to use a condom".

Poverty and orphanage were often cited as significant contributors to teenage pregnancies. Many female participants were from families that struggled to keep them in schools or provide them with all their needs. Some girls had lost both their parents and were left with no one to support them. Thus, some girls engaged in transactional sex in order to sustain their lives.

\section{Access to contraceptives}

The participants highlighted that it was difficult for teenagers to access contraceptives. Teenage mothers reported negative attitudes towards them from HCWs and shop keepers when they inquired about contraception. They also reported fear and shame when accessing condoms, since they are usually at the front desk where everyone is looking or handed over by an adult at the clinic or at shops. Furthermore, some reported being denied condoms at the shops.

\section{Perception of contraception}

Many teenagers have misconceptions and negative feelings towards modern contraception. In addition, teenage mothers reported that modern contraception (pill, IUD, injection etc.) 
may results in many adverse outcomes such as infertility, or even cancer. Others highlighted misconceptions about who can utilize contraception and when it can be used.

\section{Reflection on teenage pregnancy}

The teenage mothers stressed that teenage pregnancy resulted in many negative outcomes. For instance, many teenage mothers had to drop out of school to take care of their child. A respondent further highlighted that the first pregnancy is often followed by another, since the teenage mother is out of school and has no other future plans than to build a family.

Suggestions to prevent teenage pregnancy and provide youth-friendly services at the clinic

\section{Education on safe sex}

Most of the teenage mothers suggested educating teenagers on safe sex and contraception as a way to tackle teenage pregnancy. Teenage mothers urged the parents not to hide the truth and speak openly about these issues. They also mentioned health care workers and teachers as sources of reliable information. The teenage mothers suggested that sexual education should take place in communities, schools and clinics. Sensitizing rural health motivators (RHMs) around the issue of teenage pregnancy was also highlighted has a good way to reach the entire community.

\section{Promote abstinence}

Preservation of virginity or abstinence was promoted by most participants, but its benefits were not well understood. It seems that abstinence is associated with making a partner happy in the future, spiritual fulfilment and societal norms, values and obligations. Awarding girls who preserve their virginity could help promote abstinence and encourage others to abstain.

\section{Encourage youth-friendly clinics}

The respondents suggested that in order to prevent teenage pregnancy and provide youthfriendly services, nurses should be encouraged to interact with teenagers in a friendly manner. The teenage mothers rated the services from Nkalashane Clinic as friendly; however, this was not the case for other clinics in the area. Nurses were also urged to provide contraception services without judging the teenagers as well as respecting the patient's right to privacy by keeping the information and service confidential.

\section{Quantitative findings: questionnaires among at-risk youth}

The average age of participants was 16 years in each school. Most participants reported having a strong family and friend network, and had a low emotional state score (6.5 for the girls and 7.9 for the boys), and $17 \%$ of the girls and 19\% of the boys were screened depressive by the EST-Q1 (i.e. emotional state score $>11$ ).

In terms of the knowledge of the participant on sexuality and contraception, most of the participants reported being "somewhat knowledgeable" (76\% among girls, 69\% among boys; Table 2.1). Both at-risk girls and boys reported learning about sexuality from their parents ( $51 \%$ and $38 \%$, respectively) or a teacher at school (54\% and $47 \%$, respectively). At-risk girls and boys further reported feeling comfortable turning to their parents ( $44 \%$ and $31 \%$, respectively) or a $\mathrm{HCW}$ ( $46 \%$ and $28 \%$, respectively) for information about contraception and safe sex.

In terms of knowledge on safe sex and contraception, most of the high school (83\%) and secondary school (77\%) students self-reported as "somewhat knowledgeable", $42 \%$ of the primary school students self-reported as "not at all knowledgeable". The average score of the participants on sexual knowledge was 8 out of 11 . However this study highlighted that there is still confusion around safe sex and contraception. For instance, $41 \%$ of the at-risk girls and $38 \%$ of the at-risk boys thought that modern contraception (condoms, pills, etc.) can make you infertile. In addition, $27 \%$ of the at-risk girls and 38\% of the at-risk boys thought that birth control pills, injectable or IUDs can help prevent sexually transmitted infections (STIs), including HIV/AIDS. Despite having the same average age, the primary school students 
average sexuality knowledge score was lower (7.3), compared to secondary (8.6) and high school (9.5) students. The primary school students were even more confused about the safe sex and contraception issues than the secondary and high school students. For instance, $75 \%$ of the primary school students believed that drinking water after having unprotected sex prevents unwanted pregnancies, and 54\% thought that, to be extra safe, it is better to use two condoms at once.

The participants were asked to cite all the contraception methods they know, and 78\% of the at-risk girls and $69 \%$ of the at-risk boys were able to cite at least one correct method of contraception, mainly condoms ( $97 \%$ of the girls, $100 \%$ of the boys) and pills ( $72 \%$ of the girls, $50 \%$ of the boys). On the other hand, $39 \%$ of the at-risk girls and $28 \%$ of the at-risk boys cited at least one ineffective method of contraception. Seven respondents mentioned withdrawal, six mentioned HIV prevention methods (such as "do not share needles" or "circumcise”), four mentioned social behaviours (such as "as a girl not going out at night") and two respondents mentioned "safety period" as a method of contraception. In addition, only $50 \%$ of the primary school students were able to cite at least one correct method of contraception.

\section{Challenges faced by the facility staff to prevent teenage pregnancy}

Seven of the 9 facility staff at the Nkalashane Clinic were enrolled in the study. The two staff members that were not enrolled were the principal investigator and a nurse that was unavailable at the time of the study. As shown in Table 3.1, the majority of the facility staff is female (71\%), aged between 28-48 years and had children (86\%). Of those who were parents, many had provided information about safe sex to their children (83\%), with the average age that their children first received such information being 11.8 years [10-13].

Most of the facility staff (71\%) was comfortable providing contraceptives for adolescents. However, they were more likely to provide counselling and education to 12 year old clients compared to a 16 year old.

Some workers were not comfortable providing contraceptives to teenagers in general (29\%), and many were against providing emergency contraception (71\%), and against abortion (86\%).

\section{Discussion}

\section{Risk factors for teenage pregnancy}

\section{Socio-demographics}

Family characteristics are important in determining risk for teenage pregnancy. The majority of the parents (mothers and fathers, 63\%) of teenage mothers were either uneducated or only completed primary school. Low education levels of the parents may influence teen pregnancy considering that $19 \%$ of teenage mothers and $25 \%$ of teenage fathers received information from their parents on sexuality, contraception and safe sex. In addition, the literature highlights that teenagers whose parents are more educated are less likely to become pregnant (Kirby et al. 2007). Moreover, a large proportion of teenage mothers (42\%) had a family history of teenage pregnancy. This is not surprising as other studies found that, compared with teenagers with no family history of teenage pregnancies, teenagers whose mother had a teenage birth were significantly more likely to experience a teenage pregnancy (East et al. 2007, Kirby et al. 2007, Chagas et al. 2009).

\section{Education level}

Teenage mothers' education level was also identified as a risk factor, as 54\% of teenage mothers were either in primary school (19\%), or were working/unemployed/out-of-school (35\%) at the time of their first pregnancy. Although this does not speak to their physical age, the level of education of the teenage mothers can be paralleled to their knowledge of sexual education. Indeed, even if the primary school students had on average the same age as the 
secondary and high school students, their knowledge on contraception and safe sex was much lower. In addition to low education level being a risk factor for teenage pregnancy, teenage pregnancy is also a risk factor for not completing high school. Out of the 27 teenage mothers who were in school at the time of pregnancy, only 5 (19\%) went back to school, often leading to a perpetual cycle of repeated pregnancies.

\section{Intergenerational Sex / Partner demographics (Teenage mothers only)}

In general, the partners of teenage mothers were 5.2 years older, had at least a secondary school degree (65\%), and were the main source of financial support for $72 \%$ of participants. These partner demographics make it very difficult for a teenaged girl to voice her opinion on (1) sexual debut (only 30\% of teenage mothers said they had sex for the first time because they were ready), (2) the use of contraception (26\% of teenage mothers said their partner not wanting to use condoms was a reason for not using protection; and $46 \%$ of teenage mothers indicated that they thought their partner wanted them to get pregnant, or they did not care if they fell pregnant), and (3) important decisions that affect their relationship (70\% reported they did not have control). None of the above was true for teenage fathers, which greatly speaks to gender inequality, the need to empower young women, and to have young men support the empowerment of young women.

Both quantitative and qualitative research findings from this study showed that women often assert that accepting financial or material assistance from a man means accepting sex on his terms, which very often means sex without condoms. Some of the transactional sex is perceived to be caused by extreme vulnerability like lack of food or shelter ("You go to school on an empty stomach and meet a boy who will offer to feed you in exchange for sex."). However, it is also came out from the FGDs that some engaged with older men for more social or materialistic gains such as fitting in with a group of friends or getting a phone (" $A$ boy will say she should have a relationship with him and he would give him the cellphone. The girl will oblige.").

\section{Knowledge of pregnancy and contraception}

The knowledge, or rather lack of knowledge about pregnancy and contraception clearly came across as one of the leading risk factors for teenage pregnancy. Less than 50\% of teenage mothers used contraception at the time of first pregnancy and the main reason cited for not using contraception was that they did not know that they could get pregnant (68\%) or they did not know about contraception (47\%). This is similar yet less prominent among at-risk youth who are already sexually active, with the majority ( $80 \%$ of girls, $75 \%$ of boys) indicated that they always/often use contraception, with $40 \%$ of at-risk girls reporting that they did not think they could get pregnant, yet none reported that they did not know about contraception.

Specifically related to contraception knowledge and misconceptions, a large proportion of teenage mothers and fathers reported they were "not at all knowledgeable" about contraception, sexuality, and safe sex at the time of first pregnancy (42\% among teenage mothers, 38\% among teenage father). Interestingly, the majority of at-risk youth reported being "somewhat knowledgeable", more knowledgeable than teenage parents; however, when asked about types of contraception $37 \%$ of at-risk girls and $21 \%$ of at-risk boys cited at least one ineffective method of contraception (compared to 14\% of teenage mothers and $25 \%$ of teenage fathers). This inflated perception of self-knowledge by the youth may be concerning, as at-risk youth also scored lower on the sexuality knowledge questionnaire than teenage parents, with a large proportion of at-risk youth believing that modern contraception makes you infertile, that injectable/IUDs/birth control pills can prevent STIs including HIV, and that drinking water after having unprotected sex prevents unwanted pregnancies.

Another misconception concern is the proportion of teenage mothers (12\%), teenage fathers (25\%) and at-risk youth (10\%) that listed withdrawal as an effective method of contraception. In addition, approximately $25 \%$ of teenage mothers and fathers, and $26 \%$ of 
the at-risk youth thought that "to be extra safe, it is good to use 2 condoms once". These misconceptions and misinformation are directly related to risk of pregnancy, as withdrawal is not an effective method, and using 2 condoms at once could lead to condoms breaking (25\% of teenage mothers and $13 \%$ of teenage fathers listed this as the reason for what went wrong when they used contraception at the time of first pregnancy).

Teenage parents reported having several sources of information about contraception and safe sex, which call into question the quality of information the teenagers are receiving. For example, the majority of teenage mothers and fathers indicated receiving information from HCWs at the clinic/school health, and at-risk youth indicated they were most comfortable approaching a HCW for information. However, the at-risk youth also indicated that the messages received from the clinics included: "they engage us on abstinence", "they always discourage having sexual intercourse while young...", "they warn school going kids against sexual activities and promote prevention". It is concerning that the key messages being shared to the at-risk youth are solely regarding abstinence, rather than education. Teenage parents and the majority of at-risk youth also indicated receiving information from their teachers; however, given that the Life Skills Education curriculum is not rolled-out at all schools or in pre-service training, we cannot be certain that the messages teachers are sharing are uniform and in line with the $\mathrm{MOH}$ recommendations. Teenage parents and some at-risk youth indicated internet and radio as sources of information; however, not all information that is provided via the media can be trusted as being accurate and appropriate. Finally, teenage parents indicated receiving information from parents, as did at-risk youth; so, there is a need to ensure that parents are also receiving on-going education on contraception and are counselled on how to talk to their children about sexuality and safe sex.

\section{Social connections and pressure}

Social connections are also viewed as a risk factor for teenage pregnancy. Although only $30 \%$ of the teenage mothers said they experienced peer pressure, it was clearly elucidated from the FGDs that peer pressure resulted in early sexual debut and transactional sex ("We are victims of peer pressure sometimes, a friend will tell you that if you want money you should get into unhealthy relationships"- FGD Teenage mother). Teens are more likely to have sex if their peers are older, use alcohol or drugs, or engage in other negative behaviour (Kirby et al. 2007). Similarly, they are more likely to have sex if they believe their friends have more positive attitudes toward childbearing, have permissive values about sex, or are actually having sex (Kirby et al. 2007).

Besides, numerous studies have found relationships between emotional distress or teens' use of alcohol and an increased likelihood of having sex, risky sexual behaviours, and pregnancy (Kirby et al. 2007, Saewyc et al. 2004). In this study, 74\% of teenage mothers had high emotional state scores, indicating that they were depressed at the time of first pregnancy, and $88 \%$ of teenage fathers would drink alcohol. In addition, sexual abuse was reported by both teenage mothers and at-risk youth with $26 \%$ of the teenage mothers reported being pressured into their sexual debut, and $28 \%$ of them reported being a victim of sexual violence. The majority of the sexually active at-risk youth indicated that they were pressured into their sexual debut, and $10 \%$ were victims of sexual violence. These findings relate with the literature, which report that teenage pregnancy is strongly linked to sexual abuse (Kirby et al 2007, Saewyc et al. 2004).

It was also reported in the literature (Kirby et al 2007) that teenagers who live with both parents and enjoy close relationship with them are less likely to have unprotected sex and become pregnant. However, only $56 \%$ of the teenage mothers in this study said they had a strong social network at the time of the first pregnancy. In addition

many teenage mothers and at-risk youth highlighted not receiving attention or care from their parents, due to orphanage or not living with their parents: "Some kids will feel like they are not getting any love from their parents hence when a boy comes along, she will see the boy as a potential source of love not knowing his motives” FGD Boys High school. 
Hence, the findings of the study indicated that teenagers felt unsupported in various aspects in life including socially, emotionally, economically and educationally. However, the teenagers are still expected to take precautions and be responsible ("Children [should] preserve themselves and behaves healthy" FGD Teenage mother). For instance, teenagers (especially girls) face contradictory societal pressures to preserve their virginity, while also feeling pressured to engage in sexual intercourse to satisfy a partner or to fit-in with a group of friends.

\section{Access to healthcare/contraception}

This study highlighted the perspective of the facility staff from the Nkalashane Clinic about teenage pregnancy. It was stressed that in addition to nurses, the orderlies and the community workers are providing either counselling about safe sex or access to contraceptives ("I cannot initiate [on family planning services] but if the adolescent wants [condoms], I can provide" Orderly). Even if they were not always comfortable providing contraception to teenagers (29\%), all of the facility staff stated that they will provide it if it was requested. In addition, they admitted that they do not always offer HIV testing and counselling to teenagers between the ages of 12-18 (although the 2015 Integrated HIV Management Guidelines indicate that a 12 year old can consent to testing, and with PIHTC, everyone should be offered a test when they come to the facility).

In addition, the facility staff seems to discuss or educate clients more often about contraceptive methods that are either available, in-stock or familiar with. According to the facility staff, birth control pills, condoms, and injectables are only type of contraceptives provided to the clients at Nkalashane Clinic. This can result in the nurses being less familiar with other forms of contraception, and as a result the community being less familiar with other contraception options.

\section{Limitations}

This study has some limitations. Firstly, small sample sizes, difficulties in reaching the teenage fathers, and no enrolment of at-risk out-of-school youth prevented a comprehensive analysis of the issue of teenage pregnancy in Nkalashane. Also, the low level of literacy of some of the participants might have resulted in difficulty in answering the questionnaire. Furthermore, it is possible that social desirability and limited truthfulness of respondents to sensitive questions such as sexual activity and behaviours or sexual violence resulted in under-estimation of sexual activity and behaviours or sexual violence. The instruments used for this study, such as the EST-Q to measure symptoms of depression, do not substitute for clinician determined diagnoses and thus depression rates should be interpreted with caution. Finally, even if the findings of the study can be generalised to rural areas with similar characteristics to Nkalashane, they may not be generalized to the entire young population of Swaziland.

\section{Recommendations}

This study yields evidence of teenagers' perspective on the role of the health sector and interventions that they believe are suitable to address the issue of teenage pregnancy in the Nkalashane area.

\section{MOH, MOET, Community collaboration}

Teenage mothers/fathers, at-risk youth and facility staff all stated that promoting better collaboration between schools, clinics and communities would help prevent teenage pregnancy. Strengthening education and in-service trainings on contraception for all facility staff, not only nurses, will assist with providing comprehensive and

accurate information about the effectiveness and risks associated with all contraceptive methods available to clients in Swaziland. In addition, building and strengthening the 
relationship between schools and clinics through the MOH and MOET, will encourage young people to access health services.

\section{Life skills education/Comprehensive sexuality education}

The need for comprehensive sexuality education for all (HCWs, parents, in- and out-ofschool youth) in every sphere of life was highlighted in this study. Providing age-specific educational messages and strengthening messages for the youth that is not sexually active should also be priority. Since parents were found to be one of the primary sources of information around sexuality, it is highly important to provide the right information to both parents and youth. Additionally, it is very important to roll out the life skills education in all school levels, even primary schools, since some older students are attending the schools and their knowledge scores are lower. Another recommendation is to strengthen the involvement of men in interventions and provide information to both male parents and male teenagers.

\section{Contraception}

The importance of proper use of contraception also needs to be emphasised. Condoms were the main method of contraception used by participants, and the majority of at-risk youth indicated that it is easy to access condoms. However, they also said that condoms should be placed in easily accessible areas. Participants also cited issues with effective condom use including condoms breaking (potentially because they were not using them properly). Among the at-risk youth who were sexually active but not using condoms, girls reported not having any on hand at the time (which could be improved with accessibility) or that they did not believe in them (which could be addressed with education), while boys indicated that they did not want to use them (this should also be addressed with education on the importance of using condoms to protect against not only pregnancy but STIs). In addition, the information shared around contraception commodities (side effects, dosing schedule, etc.) needs to be clarified and standardised. Indeed, misconceptions and lack of knowledge resulted in some cases in teenagers being scared away from modern contraception and turning to less effective traditional methods. It was also found that comprehensive contraception information is only provided after the first pregnancy, once the women go to their antenatal care (ANC) visits and are enrolled in family planning services. At-risk youth also reported that "Family Planning" is not the preferred term for contraception services, since the youth disassociate themselves with the thought of having families and planning. Therefore, the $\mathrm{MOH}$ may consider re-branding "Family Planning" as part of the ongoing youth friendly services initiative.

\section{Psychosocial Support}

Many teenagers were either found to be depressive or reported being survivors of sexual violence. It is crucial that youth are provided with access to culturally appropriate psychological care (Saewyc et al. 2004).

Even though peer pressure was highlighted as a risk factor for teenage pregnancy, there may be an opportunity to harness it for a positive impact because it is observed to be the best channel in reaching young people. While peers may indeed steer each other in dangerous directions, their social interaction also fuels other types of influence: support for each other, modelling of different behaviours, and trust that is more freely given (Medley et al. 2009, Odundo et al. 2013). Hence, peer pressure should be encouraged along with provision of the right information to children for them to influence each other positively. Thus, pursuing the integration of peer education into school extracurricular activities, identifying and training selected teachers as patrons of peer education clubs, developing peer education manuals, and extending peer education to out-of-school youths could be the next steps to follow in order to promote positive peer pressure (Odundo et al. 2013). 
Texila International Journal of Public Health

Volume 4, Issue 4, Dec 2016

\section{Youth Friendly Services}

Currently, it seems that young people receive and accept the healthcare services offered to them but are not advocating for an increase in the quality and diversity of services, particularly for sexual and reproductive health for youth. The following recommendations for better youth-friendly services were provided by the youth from Nkalashane:

- Open the health facilities on the weekend for youth to access services freely, because the youth are not comfortable being seen wearing school uniforms when accessing FP services during the week. The facility staff at Nkalashane also agreed that this would be useful.

- Keep condoms can in private places (like toilets) instead of waiting areas, because young people tend to be scared to pick them up from public places.

- Not having services-specific rooms, such as a "Family planning room", will help reducing stigma and discomfort brought from being seen queuing for specific services.

- Ensure code of conduct among HCWs (some participants complained about HCWs using cell phones while attending to clients and refusing to see clients), and implement a rotation of the nurses to prevent the sharing of confidential information was also suggested.

The at-risk youth indicated that they were most comfortable asking healthcare workers/school health for information on sexuality, contraception and safe sex so it is imperative that the HCWs are sharing educational and unbiased information with the youth. This aligns with the MOH's youth friendly services (YFS) approach which is currently capacitating nurses on providing services to youth. The primary goal is to encourage young people to access health services without feeling judged or ridiculed for their personal choices or health care needs. During the training, emphasis is placed on maintaining separation between the personal values of a HCW, and their ethical responsibilities as a health provider, as value judgments have been identified by adolescents as the greatest barrier to their accessing services. This will improve upon the status quo, where many facilities have only a 'youth-friendly corner' and, at most, a single staff member trained to positively interact with adolescent clients. All four regions have been reached with these trainings, with an average of 38 nurses per region to date. The head nurse at the Nkalashane Clinic attended the YFS training, which was part of the reason for embarking on this study. The Sexual and Reproductive Health Unit (SRHU) is targeting training at least $80 \%$ of nurses in each health facility, to ensure a youth-friendly environment. The findings from this study suggest all facility staff, in addition to HCWs, should be trained on YFS as the youth will ask whoever is available at the facility.

\section{Conclusion}

All Swazis of any age or status deserve to have access to friendly, appropriate, clientoriented, and affordable sexual and reproductive health services. However, these services in Swaziland apparently failed to meet the needs of adolescents. Many of the risks factors of teenage pregnancy highlighted in this study could be addressed by continued sex education to both teenagers and adults throughout the country and youth-friendly clinics

\section{References}

[1]. Aluoja A., Shlik J., Vasar V., Luuk K., Leinsalu M., (1999) Development and psychometric properties of the Emotional State Questionnaire, a self-report questionnaire for depression and anxiety. Nord J Psychiatry $\cdot$ Vol $53 \cdot$ No 6

[2]. Central Statistical Office. (2007). Swaziland Demographic and Health Survey (2006-2007). Mbabane: Central Statistical Office and Macro International Inc.

[3]. Chagas de Almeida M. C., Aquino E. M.L., (2009) The Role of Education Level in the Intergenerational Pattern of Adolescent Pregnancy in Brazil. International Perspectives on Sexual and Reproductive Health, 35(3):139-146 
[4]. Dlamini, S. (2002). The problems of teenage mothers in Southern Hhohho region of Swaziland. Pretoria: University of South Africa.

[5]. Dulitha, Nalika, Upul, Chrishantha, Alwis, Hemantha, et al. (2013). Risk factors for teenage pregnancy in Sri Lanka. Health Science Journal, (7),3.

[6]. East P. L., Reyes B.T, Horn E.J. (2007) Association Between Adolescent Pregnancy And a Family History of Teenage Births. Perspect Sex Reprod Health. 39(2): 108-115

[7]. GmbH (2015) Atlas ti 7.5. GmbH, Berlin.

[8]. Goucelea, W. O. (2009). Risk factors for Pregnancy among adolescent girls in Equador's Amazon Basin. Public Heath 26(3).

[9]. Government of Swaziland.(2010). Multiple Indicator Cluster Survey. Mbabane: Government of Swaziland.

[10]. Kirby D., Lepore G. (2007) Sexual Risk and protective factors: factors affecting teen sexual behaviour, pregnancy, childbearing and sexually transmitted disease: which are important? Which can you change? ETR Associated, The national campaign to prevent teen and unplanned pregnancy.

[11]. Liik, M., Paris, M., Vahter, L., Gross-Paju, K., Haldre, S. (2013). I-ADAM SPET imaging of serotonin transporter in patients with epilepsy and comorbid depression. BMC Neurology, 13, 204.

[12]. Medley, A., Kennedy, C., O’Reilly, K., Sweat, M. (2009). Effectiveness of Peer Education Interventions for HIV Prevention in Developing Countries: A Systematic Review and Meta-Analysis. AIDS Education and Prevention : Official Publication of the International Society for AIDS Education, 21(3), 181-206.

[13]. Microsoft Corporation (2010) Microsoft Access 2010. Microsoft Corporation.

[14]. Ministry of Health (2012) National Health Sector Strategic Plan (NHSSP) 2008- 2013 Mid-Term Review Report. Ministry of Health, Mbabane, Swaziland

[15]. Odundo, P. A, Anjuri, D. Odhiambo, T. (2013) Impact of peer education on HIV/AIDS behaviour change among secondary school youths: a static group comparison analysis of a peer education project in Rachuonyo County, Kenya. The Lancet, Volume 381, S101

[16]. Ööpika P, Aluojab A., Kaldaa R., Maaroosa H-I.(2006) Screening for depression in primary care. Family Practice; 23: 693-698.

[17]. Saewyc E. M., Magee L. L., Pettingell S. E., (2004) Teenage Pregnancy and Associated Risk Behaviors Among Sexually Abused Adolescents. Perspectives on Sexual and Reproductive Health. Volume 36, Number 3.

[18]. Sodi, E. (2009). Psychological Impact of teenage pregnancy on teenage teenagers. Limpopo, South Africa: School of Social Sciences, University of Limpopo.

[19]. StataCorp. (2011). Stata Statistical Software: Release 12. College Station, TX: StataCorp LP.

[20]. WHO.(2014, October). Maternal, newborn, child and adolescent health. Retrieved October 2014, from WHO Website: www.who.int/child_adolescent_health/en/ 